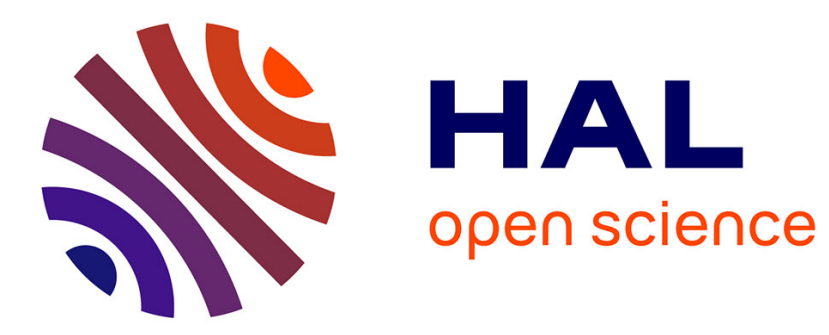

\title{
FIB manufactured microstructures with low Coefficients of Thermal Expansion
}

\author{
Eva Héripré, Marwen Mehrez, Andrei Constantinescu
}

\section{To cite this version:}

Eva Héripré, Marwen Mehrez, Andrei Constantinescu. FIB manufactured microstructures with low Coefficients of Thermal Expansion. Mechanics Research Communications, 2021, 10.1016/j.mechrescom.2021.103667 . hal-03128107

\section{HAL Id: hal-03128107 \\ https://hal.science/hal-03128107}

Submitted on 2 Feb 2021

HAL is a multi-disciplinary open access archive for the deposit and dissemination of scientific research documents, whether they are published or not. The documents may come from teaching and research institutions in France or abroad, or from public or private research centers.
L'archive ouverte pluridisciplinaire HAL, est destinée au dépôt et à la diffusion de documents scientifiques de niveau recherche, publiés ou non, émanant des établissements d'enseignement et de recherche français ou étrangers, des laboratoires publics ou privés. 


\title{
FIB manufactured microstructures with low Coefficients of Thermal Expansion
}

\author{
Eva Héripréa ${ }^{\mathrm{a}}$, Marwen Mehrez ${ }^{\mathrm{b}}$, Andrei Constantinescu ${ }^{\mathrm{b}}$ \\ ${ }^{a}$ MSSMat, CNRS-Université Paris-Saclay, CentraleSupelec France \\ ${ }^{b}$ LMS, CNRS-Ecole Polytechnique, Institut Polytechnique de Paris, France
}

Keywords: FIB, coefficient of thermal expansion, metamaterial

\section{Introduction}

Natural solid materials expand when heated, as the interatomic distance increases with heat. The phenomena is transmitted across scales, both for cristalline or amorphous materials. The development of modern devices working in multi-physics environments, combining at least mechanical and thermal loadings, such as thermal engines, biomedical structures, semiconductor wafers, optical, nuclear or solar energy structures require that the employed materials have a high stability under the service loading. Uncontrolled thermal expansion between different parts of a structure can lead to high incompatible strain, localized plastic strain and finally failure and has been a subject of concern in fatigue design. Dilatation incompatibilities are at the origin of residual stresses and the consequent fatigue failure of the structures, see examples in Ref. [1] or [2] for structures in industry Ref. [3] for geological structures in nature.

Designing materials and structures with specified coefficients of thermal expansion (CTE) and particularly with low or negative CTE is of peculiar interest. Materials with low CTE can be obtained by either (a) tuning an appropriate material, for example by manipulating the chemical composition (see Ref. [4]), introducing in-situ secondary phases into a matrix Ref. [5], etc. or by (b) employing a micro-architectured material structure. The concepts of microstructured materials with low CTE have already been sketched in Ref. [6] and obtained by mathematical shape optimization in Ref. [7] and later manufactured at the macroscopic scale [8, 9, 10]. At the microscopic scale thin films with low CTE were microfabricated from titanium and aluminum films in Ref. [11]. Most of these examples are planar, i.e. 2D structures as discussed on a series of lattice examples in Ref. [12]. However recently 3D proposals have emerged, like the origami type structures Ref. [13], the bimaterial lattice structures discussed in
Ref. [14], or the lattice structure obtained from printed polymer structures reported (see Ref. Qu:2016hg). Let us further remark that more generally the control of the CTE permits to design foldable structures, denoted also as $4 \mathrm{D}$ printing, as shown in Ref. [15].

The objective of this work is to demonstrate that structures with low CTE's can also be manufactured at the micrometric scale using tradintional milling and welding using a focused ion beam (FIB). In order to reach this target, we started from previous theoretical work reported in [8] and experimental work at the large scale, e.g. Ref. [10] where a bi-material structure was proposed, tested and scaled down an similar shape at the microscopic scale. In this paper, starting from two micrometric sheets of steel and aluminum, we milled the basic elements of the unit cell and welded final unit cell of the architectured microstructure. The heat expansion coefficient was determined using digital image correlation during the heating up of the microstructure on a heating element in a scanning electron microscopy (SEM). It is reported that specimen exhibits a thermal expansion coefficient significantly lower than either of the constituent materials. Moreover the realized structure is an example of structures which can be constructed using the facilities of the Focused ion beam (FIB).

The paper is organized as follows. The next section presents the design of the sample and discusses briefly several unit-cell proposed in the literature. It continues with the description of the materials and the manufacturing of the sample. In Section 3 are presented the heating experiments and the measurements of the thermal expansion coefficient while in Section 4-5 are discussed these results. A summary of main findings are given in Section 6. 


\section{Sample: design and manufacturing}

The design discussed next draws its inspiration from Ref. [8]. This work showed that two- or threedimensional lattices trusses can exhibit a global homogenized CTE global smaller than the ones of its components. The simplest pattern can be designed using a unit cell combining a triangle and a hexagonal shape with CTE's $\alpha_{1}$ and $\alpha_{2}$ respectively. The complete lattice will exhibit a small CTE if the condition $\alpha_{1}<\alpha_{2}$ is satisfied. Next we shall replace the inner triangle trusses with a triangular plate, see Figure 6 The underlying mechanism creating the small CTE is triggered by a larger thermal expansion of the inner triangle which imposes an inward rotation of the outer trusses and induces an overall contraction of the non-connected vertices of the hexagon. The periodic reproduction of the unit cell (UC) creates a structure with vanishing CTE.

Moreover, Ref. [16] provided the analytic expression for the global homogenized CTE, $\alpha$ in terms of the material and structural value of the constituents. For pinned lattice structure, we have:

$$
\frac{\alpha}{\alpha_{1}}=\frac{1-\frac{1}{2}\left(\frac{\alpha_{2}}{\alpha_{1}}\right)(\sin 2 \theta)\left(\frac{1}{\sqrt{3}}+\tan \theta\right)}{1-\frac{1}{2}(\sin 2 \theta)\left(\frac{1}{\sqrt{3}}+\tan \theta\right)}
$$

where $\theta$ is the skewness, an angle characterizing the geometric construction and $\alpha_{1}, \alpha_{2}$ denote the CTE of the trusses and polygons respectively. For a bonded structure, we have:

$$
\begin{aligned}
& \frac{\alpha}{\alpha_{1}}=1-\left(C_{1} \tan \theta-12 \sqrt{3}\right)(\cos \theta+\sqrt{3} \sin \theta)\left(\frac{\alpha_{2}}{\alpha_{1}}-1\right) \times \\
& \left(C_{1}(\sqrt{3} \cos \theta-\sin \theta)+12\left(\sqrt{3}+2 \frac{E_{1} A_{1}}{E_{2} A_{2}}\right)(\cos \theta+\sqrt{3} \sin \theta)\right)^{-1}
\end{aligned}
$$

where $C_{1}$ is a relative bending stiffness and $E_{i}, A_{i}, i=$ 1,2 are the Young modulus and the area of the trusses of the materials. The design possibilities in terms of attainable CTE's are represented in Figure 6 and show that values of negative or vanishing CTE's can be obtained with these structures.

This design procedure was successfully manufactured and tested in [16] on lattice structures with angle $\theta \approx 30^{\circ}$ titanium trusses $\left(\alpha_{1}=8.6 \mathrm{ppm} /{ }^{\circ} \mathrm{C}\right)$ and aluminum $\left(\alpha_{2}=23.1 \mathrm{ppm} /{ }^{\circ} \mathrm{C}\right)$ plates (resulting in a unit cell with $\alpha \approx 2.56 \mathrm{ppm} /{ }^{\circ} \mathrm{C}$ ) with a unit cell diameter of $12.4 \mathrm{~mm}$. The complete lattice structure had a CTE of $2.56 \mathrm{ppm} /{ }^{\circ} \mathrm{C}$.

The design proposed here is a scaling down of the basic unit cell to a diameter diameter of $\approx 160 \mu \mathrm{m}$ and its manufacturing from thin sheets: a steel sheet for outer truss with CTE $\alpha_{1}=12 \mathrm{ppm} /{ }^{\circ} \mathrm{C}$ and thickness of $25 \mu \mathrm{m}$ and an aluminum sheet for the inner triangle with CTE $\alpha_{2}=24.3 \mathrm{ppm} /{ }^{\circ} \mathrm{C}$ and a thickness of $15 \mu \mathrm{m}$. The skewness angle $\theta$ was equal to $26.8^{\circ}$. The estimated CTE's for both pinned and bonded lattices structures are represented by dot symbols on Figure 6 and attain theoretically homogenized CTE of $4.45 \mathrm{ppm} /{ }^{\circ} \mathrm{C}$ and $5.97 \mathrm{ppm} /{ }^{\circ} \mathrm{C}$ respectively.

In order to achieve the small size we shall use a manufacturing procedure under SEM-FIB consisted in the next steps:

(i) milling of the outer steel hexagon truss and the inner aluminum triangle. The hexagon is linked to the external support on two points to minimize bending of the final unit cell.

(ii) extraction of the inner triangle with the tungsten needle of the micromanipulator.

(iii) inlay of the inner triangle in the outer hexagon

(iv) welding of the corners of the triangle with the hexagon using a Platinum ion-induced deposition.

(v) deposition of the measurement grid by electronbeam lithography.

The manufacturing was performed on a Helios-660 apparatus combing scanning electron microscopy (SEM) observation and a Focused ion beam (FIB) high precision milling. FIB high voltage has been set to $30 \mathrm{kV}$ and the highest beam current $(65 \mathrm{nA})$ is chosen in order to minimize manufacturing time. The hexagon truss was milled in 2 hours and 45 minutes and the aluminum triangle in 45 minutes. Manipulation of the components is performed by an easylift micromanipulator and a Pt gaz injection to link components to the needle. Additionally, for the deformation tracking using digital image correlation, a gold grid has been deposted on a ThermoFisher QUANTA 600 FEG-SEM equipped with Raith Elphy Quantum electron-beam lithography system. The microgrid step is $4 \mu \mathrm{m}$.

The manufacturing procedure is illustrated in Figure 3. A precise observation of the elements of the units cell, shows that the milled geometry of the outer truss is geometrically different from the perfect truss. This is probably due to the higher milling time and power necessary to mill the truss. Small movements of the ion beam and of the structure itself caused to heating, thermal expansion and release residual stresses are another possible explanation of the difference. In contrast the milling of the aluminum triangle was better controlled and the final shape is closer to the initial design. Another defect of the milling is the varying thickness of the hexagonal truss due to matter re-deposition on the face bottom of the truss. 


\section{Experimental measurements}

Heating experiments of the complete structure have been performed in a FEI QUANTA 600F SEM (Scanning Electron Microscope) apparatus equipped with a $1000^{\circ}$ heating stage from FEI/ThermoFisher, see fig. 4 for details. A heating path with a rate of $\approx 5^{\circ} \mathrm{C} / \mathrm{min}$ with dwell times for temperature homogenization,, see Figure 6 was imposed on the structure and images have been taken at different steps and processed using digital image correlation.

The first heating test was performed only on the aluminum triangle in order to validate the procedure and to estimate the measurement errors.

The second heating test was on the complete structure of the unit cell comprising both the hexagonal truss and the aluminum triangle. The heating histories of both tests are displayed on Figure 6, where \#1 and \#2 denote the first and second test respectively.

The surface strain, $\varepsilon=\varepsilon_{i j} \mathbf{e}_{i} \otimes \mathbf{e}_{j} \quad i, j=1,2$ with $\mathbf{e}_{i}$ the unit vectors of the Cartesian coordinate system has been obtained by using digital image correclation from pictures shot in the SEM. The digital image correlation was performed using CMV software [17, 18]. Images where secondary electron images shot under the following electron beam conditions : acceleration voltage $20 \mathrm{kV}$, spot size 4 under a $50 \mathrm{~Pa}$ low Vacuum with chamber pressure. Finally 4 frames are shot within $29 s$ are combined for the final image.

The mean strain within the aluminum triangle has been computed as an average over the green area in fig. 5. The procedure was chosen to avoid errors due to the grey level variation in the image at the boundaries of the traingle due to, metal re-deposition and lightning variation. The mean strain of the non-connected vertices of the outer hexagon have been estimated from their displacements using combining measurements and computations.

\section{FEM modelling}

A finite element model of the unit cell has been constructed with Z-set software, see www.zsetsoftware.com. The material is considered to be linear thermo-elastic. The material coefficients are listed in Table 6 The 3D structure has been obtained by vertical extrusion of the upper face of the unit cell. The real shape in terms of lengths and thickness has been taken into account, (i.e. see Figure 77). The welds are considered as to be perfect and therefore the displacements of the steel truss and the aluminum triangle are perfectly bonded. The variation of the thickness of the outer truss observed by SEM, see section 2, has been neglected and the thickness is considered as homogeneous. Boundary conditions were close to the experiment imposed displacements on the hexagon holder and free surfaces. They have not been adapted for the computation of the effective material parameters of a periodic structure based on this unit cell. Figure 7 displays the initial and the deformed mesh by an amplification factor of 100 . at $100^{\circ} \mathrm{C}$, illustrating the combined expansion of the inner triangle and the contraction of the outer hexagon at the origin of the small CTE.

\section{Results and Discussion}

We shall discuss next the heat expansion experiments, test \#1 and \#2, on the sole aluminum triangular inlet and on the complete unit cell structure, respectively.

The measurement results of the heat expansion of the aluminum triangle are presented on Figure 8 One can remark a good match between the measured $\varepsilon_{11}$, horizontal strain, and the theoretical strain computed for free heat expansion. The horizontal axes is the direction of the electron beam scanning, which provides better accuracy when compared with other directions. Unfortunately, complementary experiments with a rotated specimens with respect to the scanning direction of the beam have not been performed during this experimental campaign. The estimation of the relative measurement errors as obtained by DIC on two images of the same triangle at the same temperature is equal to a maximum value of $10^{-4}$.

The measurement results of the heat expansion of the complete structure, i.e. bimaterial unit cell are presented on Figure 9 The figure also displays results from finite elements computation of the heating experiment and analytic expression of CTE given in equations (11) and (2). One can remark that the stiffness of the outer steel hexagon does not inhibit the expansion of aluminum inlet by a large amount and does not contribute by a stiffening mechanism to the low CTE of the unit cell. At small temperatures the finite element computations of the heat expansion of the unit cell provides an excellent match with the expansion measurements the aluminum inlet. This correspondance is lost with increasing temperatures, as the stiffness and the CTE of aluminum vary. It can be seen that the evolution of strain with temperature is well approximated by a second order polynomial as displayed. Not surprising, the outer steel hexagon exhibit an almost vanishing mean strain, when computed as a mean strain value on the triangle the non-connected vertices, as these vertices turn inward with the rotation of the outer trusses. The 
evolution of mean strain of the hexagon with temperature has a smaller slope when compared to evolution of the homogenized pinned or bonded lattice structure. This can be explained by the lower stiffness acting on the non-connected vertices in a free unit cell. However, unit cell's in a pattern surface are connected exactly through these vertices and the global movement is more restricted in this case. Additional aspects explain quantitative differences between the experimental results and the models: the geometrical differences in the real structure and the finite element model, as its for example the case the thickness, the temperature varying material coefficients, the effect of the welds which have been assumed as a perfect bonding, the temperature distribution in the structure assumed to be homogeneous, which is not necessary the case as its heated through direct contact of the unit cell with the heating stage, etc.

\section{Conclusion}

This work demonstrates experimentally the ability to manufacture complex thin bi-material micrometric metastructures within a FIB. From steel and aluminium with CTE's of $\alpha_{1}=12 \mathrm{ppm} /{ }^{\circ} \mathrm{C}$ and $\alpha_{2}=24.3 \mathrm{ppm} /{ }^{\circ} \mathrm{C}$ respectively, we were able to construct a unit cell, which exhibits a CTE of $0.1 \mathrm{ppm} /{ }^{\circ} \mathrm{C}$ in non-connected conditions. This values is significantly lower than the CTE of the respective constituents of the structure. The microstructure has been manufactured using a FIB by milling thin foils and welding the parts together. A finite element analysis, corresponding to the real milled shape showed to be in good agreement with the thermal expansion experiments. The results equally assess the robustness of the design sensitivity in reaching low CTE with respect to variations the shape of the unit cell.

This work is a proof of concept and opens up a complete procedure to manufacture thin metallic structures with a tunable properties. It opens up to new perspective to test the procedure on larger lattice structures containing several elementary cells and also to combine the design with other microfabrication techniques. The results can be further refined by completing the strain measurements with thermal measurments at the small scale.

\section{Acknowledgement}

This work was partially performed during the internship of M.M. in the LMS.

[1] A. Constantinescu, E. Charkaluk, G. Lederer, L. Verger, A global computational fatigue design method for structures under thermomechanical loading: Application to cast iron exhaust manifolds, Int.Journal Fatigue 26 (2004) 805-818.
[2] Amiable, S., Chapuliot, S., Constantinescu, A., Fissolo, A., A comparison of lifetime prediction methods for a thermal fatigue experiment, Int.J.Fatigue 28(7) (2006) 692-706.

[3] L. Jeannin, L. Dormieux, T. Carlioz, Nucleation of thermal cracks at the wall of a rock mass, Mechanics Research Communications 97 (2019) 57-62.

[4] J. Chen, L. Hu, J. Deng, X. Xing, Negative thermal expansion in functional materials: controllable thermal expansion by chemical modifications, Chemical Society Reviews 44 (11) (2015) 3522-3567.

[5] J. Liu, Y. Gong, J. Wang, G. Peng, X. Miao, G. Xu, F. Xu, Realization of zero thermal expansion in la(fe,si)13-based system with high mechanical stability, Materials \& Design 148 (2018) $71-77$.

[6] R. Lakes, Cellular solid structures with unbounded thermal expansion, Journal of Materials Science Letters 15 (6) (1996) 475477.

[7] O. Sigmund, S. Torquato, Design of materials with extreme thermal expansion using a three-phase topology optimization method, Journal of the Mechanics and Physics of Solids 45 (6) (1997) 1037-1067.

[8] C. A. Steeves, S. L. dos Santos e Lucato, M. He, E. Antinucci, J. W. Hutchinson, A. G. Evans, Concepts for structurally robust materials that combine low thermal expansion with high stiffness, Journal of the Mechanics and Physics of Solids 55 (9) (2007) 1803 - 1822.

[9] J. Berger, C. Mercer, R. M. McMeeking, A. G. Evans, The design of bonded bimaterial lattices that combine low thermal expansion with high stiffness, Journal of the American Ceramic Society 94 (s1).

[10] E. Gdoutos, A. A. Shapiro, C. Daraio, Thin and Thermally Stable Periodic Metastructures, Experimental Mechanics 53 (9) (2013) 1735-1742.

[11] N. Yamamoto, E. Gdoutos, R. Toda, V. White, H. Manohara, C. Daraio, Thin Films with Ultra-low Thermal Expansion, Advanced Materials 26 (19) (2014) 3076-3080.

[12] K. Wei, H. Chen, Y. Pei, D. Fang, Planar lattices with tailorable coefficient of thermal expansion and high stiffness based on dual-material triangle unit, Journal of the Mechanics and Physics of Solids 86 (2016) 173-191.

[13] E. Boatti, N. Vasios, K. Bertoldi, Origami metamaterials for tunable thermal expansion, Advanced Materials.

[14] Q. Wang, J. A. Jackson, Q. Ge, J. B. Hopkins, C. M. Spadaccini, N. X. Fang, Lightweight mechanical metamaterials with tunable negative thermal expansion, Physical review letters 117 (17) (2016) 175901.

[15] S. Pandini, N. Inverardi, G. Scalet, D. Battini, F. Bignotti, S. Marconi, F. Auricchio, Shape memory response and hierarchical motion capabilities of $4 \mathrm{~d}$ printed auxetic structures, Mechanics Research Communications 103 (2020) 103463.

[16] C. A. Steeves, S. L. dos Santos e Lucato, M. He, E. Antinucci, J. W. Hutchinson, A. G. Evans, Concepts for structurally robust materials that combine low thermal expansion with high stiffness, Journal of the Mechanics and Physics of Solids 55 (9) (2007) 1803-1822.

[17] M. Bourcier, M. Bornert, A. Dimanov, E. Héripré, J. Raphanel, Multiscale experimental investigation of crystal plasticity and grain boundary sliding in synthetic halite using digital image correlation, Journal of Geophysical Research: solid earth 118 (2) (2013) 511-526.

[18] L. Wang, M. Bornert, D. Yang, E. Héripré, S. Chanchole, B. Halphen, A. Pouya, D. Caldemaison, Microstructural insight into the nonlinear swelling of argillaceous rocks, Engineering Geology 193 (2015) 435-444.

[19] E. Gdoutos, A. A. Shapiro, C. Daraio, Thin and Thermally 
Stable Periodic Metastructures, Experimental Mechanics 53 (9)

(2013) 1735-1742. 


\begin{tabular}{llll} 
Material & Young's modulus $(\mathrm{GPa})$ & Poisson's ratio & $\mathrm{CTE}\left({ }^{\circ} K\right)^{1}$ \\
\hline Aluminum & 70 & 0.3 & $24.3 \mathrm{e}-6$ \\
Steel & 210 & 0.3 & $12 . \mathrm{e}-6$ \\
\hline
\end{tabular}

Table 1: Material coefficients used in the FE model

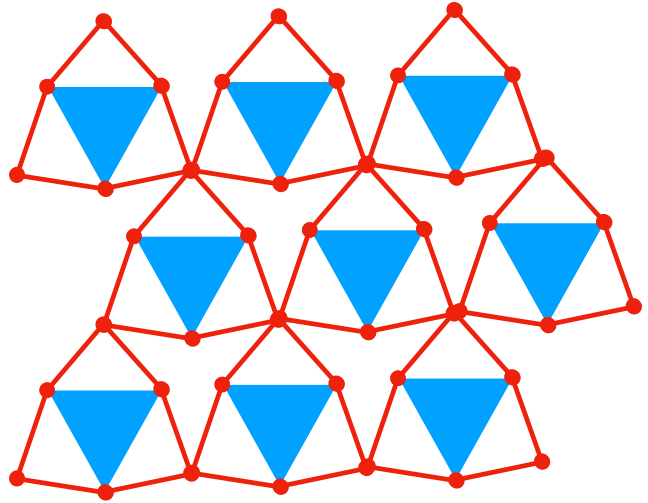

$(a)$

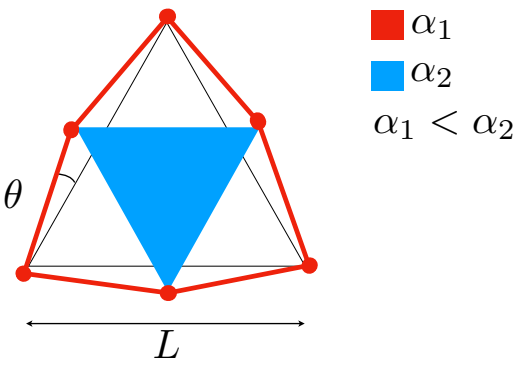

(b)

Figure 1: The bi-material structure with small coefficient of thermal expansion (CTE) consisting of rods of with CTE $\alpha_{1}$ and triangular plate with CTE $\alpha_{2}\left(\alpha_{1}<\alpha_{2}\right)$ from [16] and [19]. (a) pattern of periodic distribution of unit cells (b) unit-cell. Geometric shape parameters are $L$ the length of the edge and the skewness angle $\theta$. 


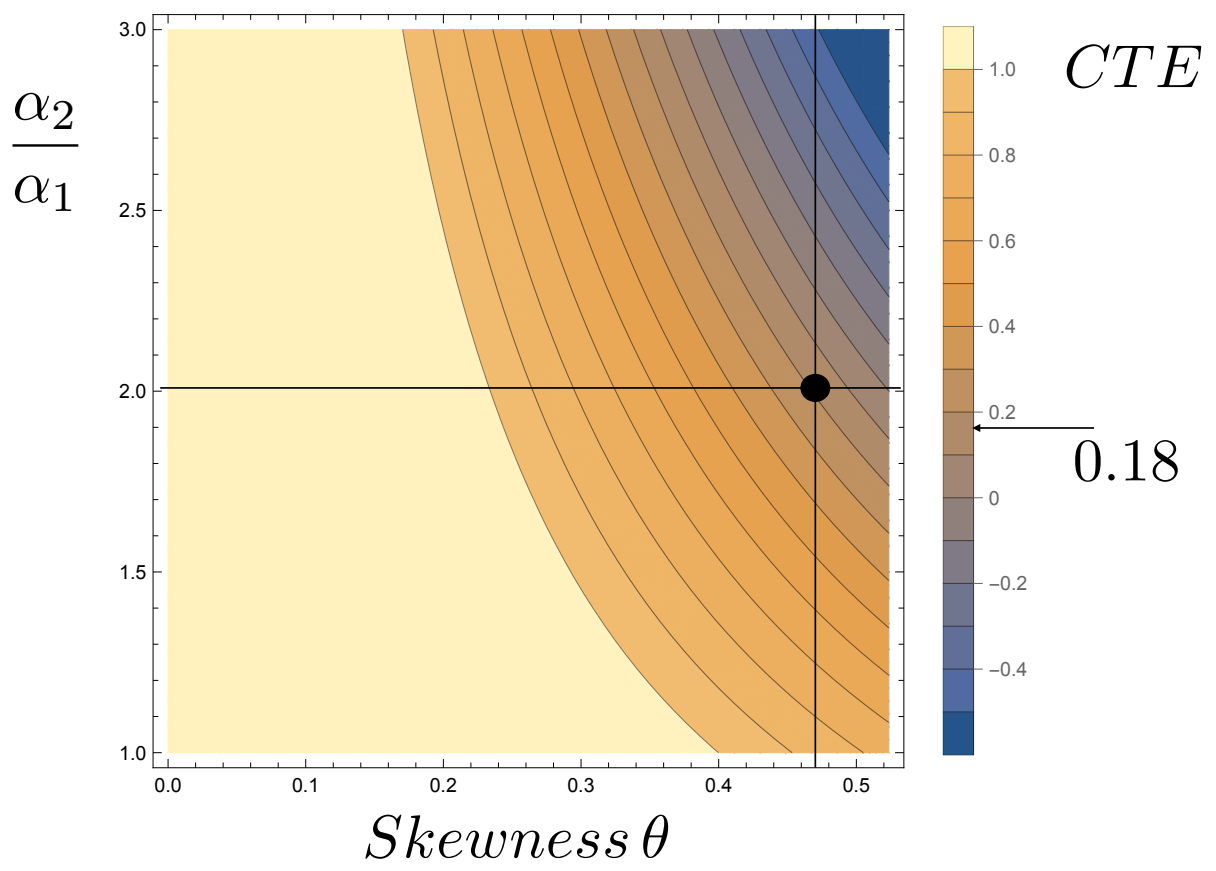

(a) pinned structure

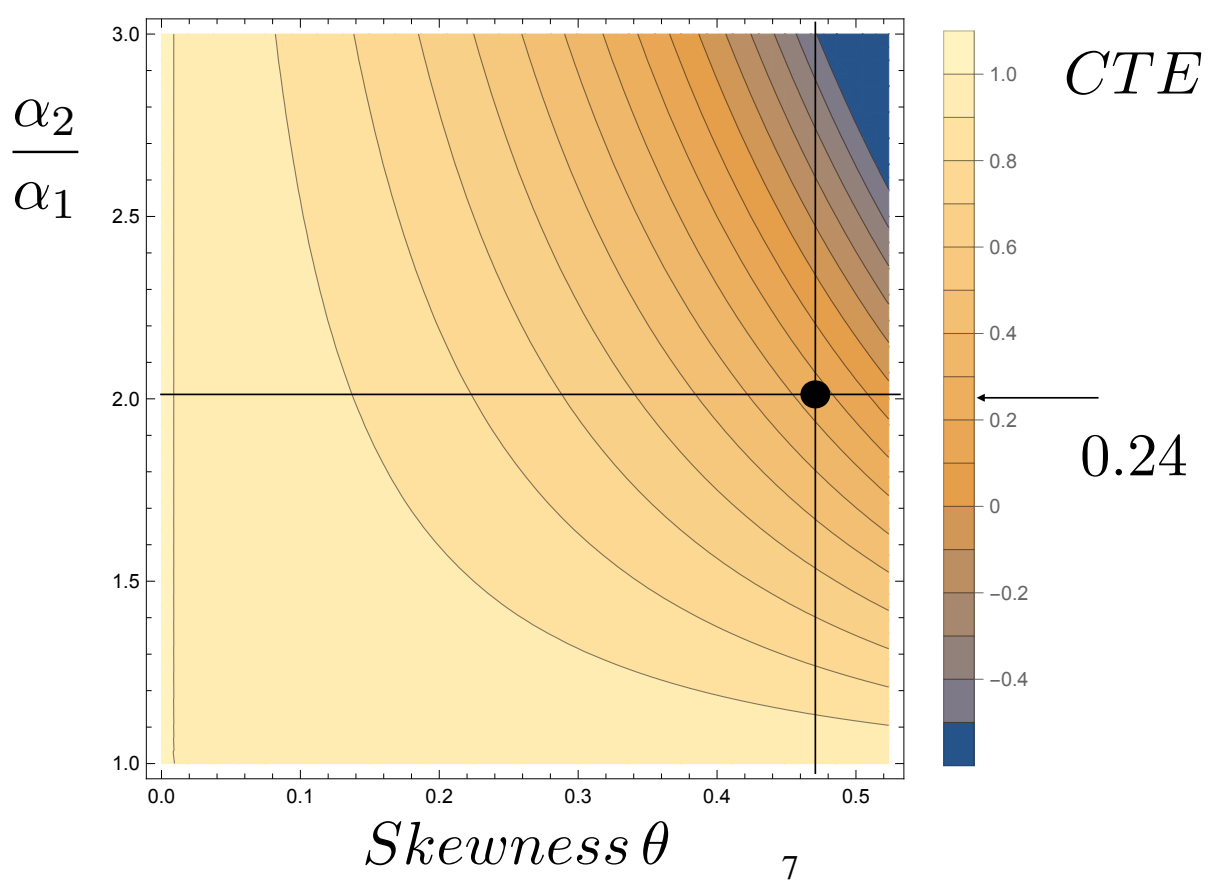

(b) bonded structure

Figure 2: Contourplots of the relative homogenized CTE $\alpha / \alpha_{2}$ in terms of the geometrical characteristic $\theta$ and the contrast of the CTE of the two materials, $\frac{\alpha_{2}}{\alpha_{1}}$, see equations [1] and [2] as well as Ref. [8]. 


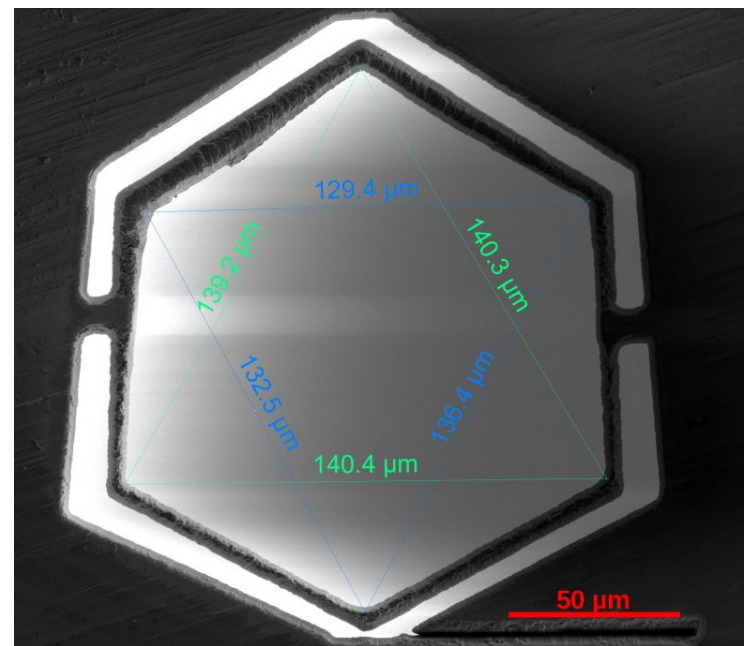

(a)

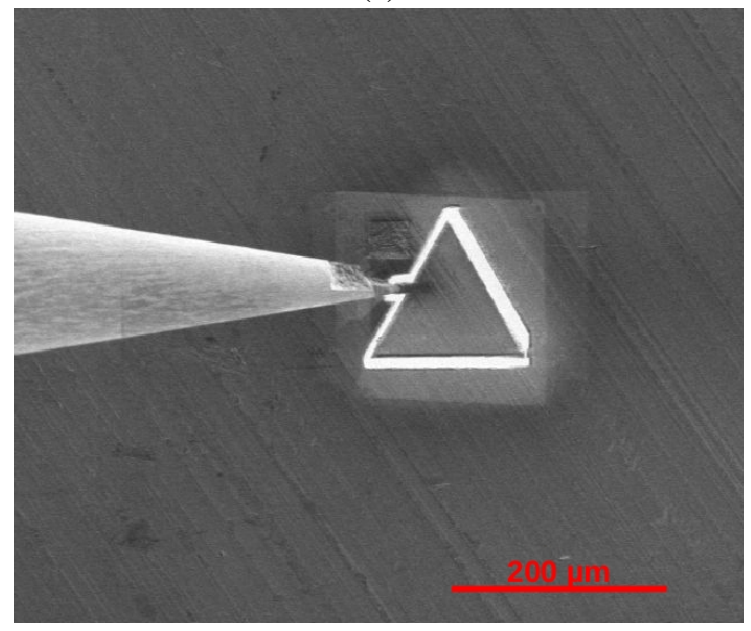

(c)

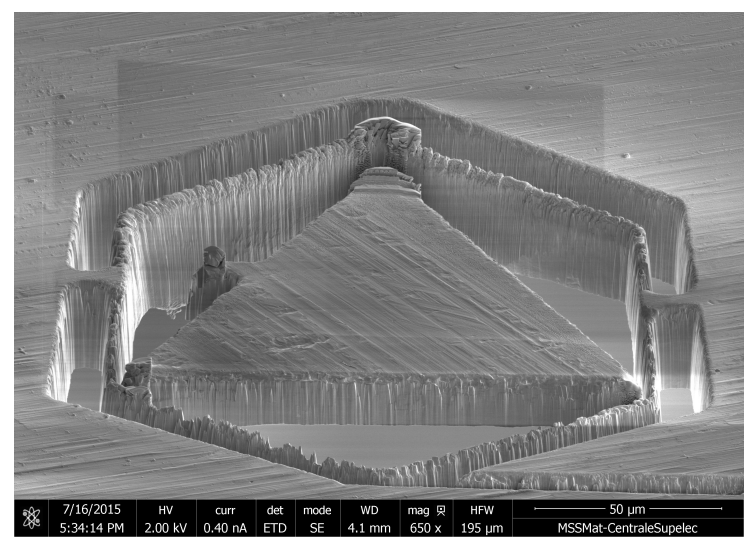

(e)

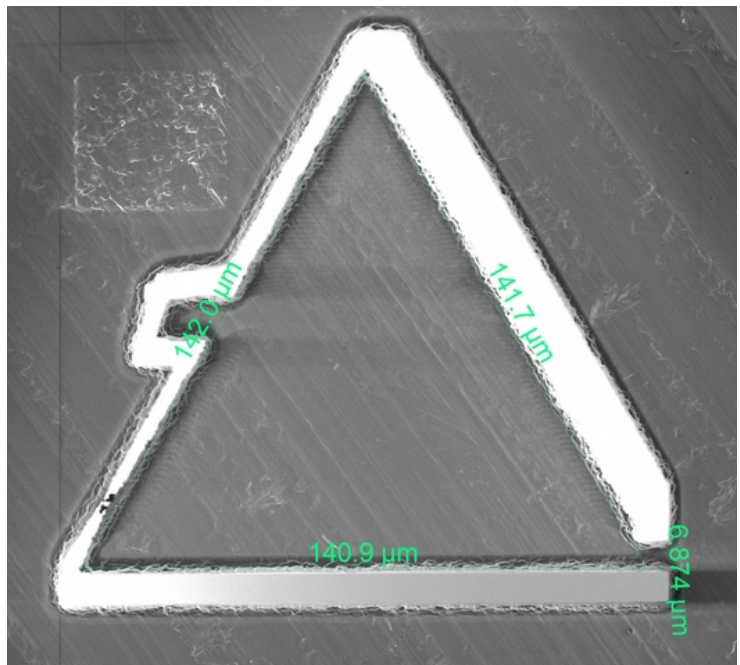

(b)

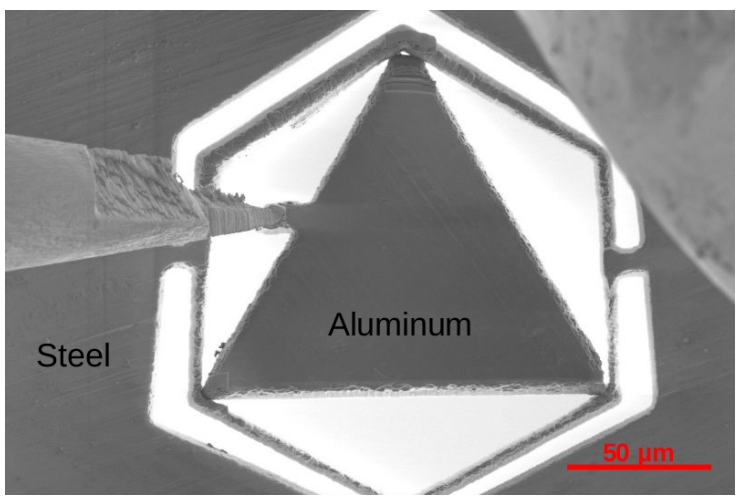

(d)

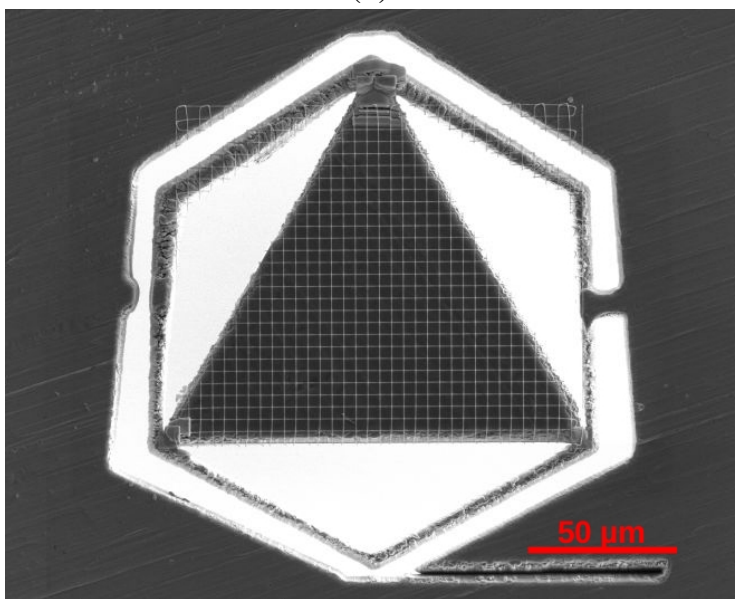

(f)

Figure 3: The manufacturing steps of structure: $(a, b)$ Final shapes of the outer hexagon and inner triangle after milling (c) extraction and inlay of the triangle, (e) final structure after welding (f) final structure with the measurement grid. 


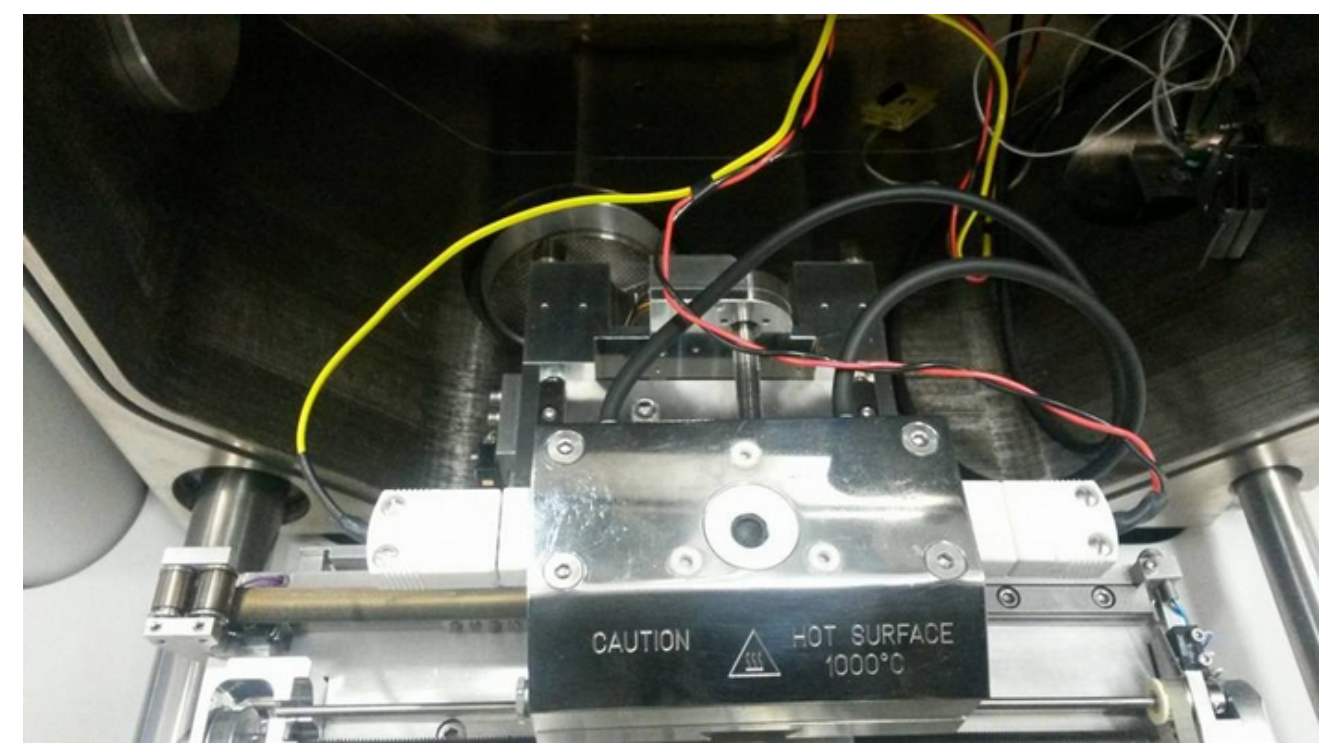

Figure 4: The heating stage at the entrance of the SEM chamber with the specimen holder.

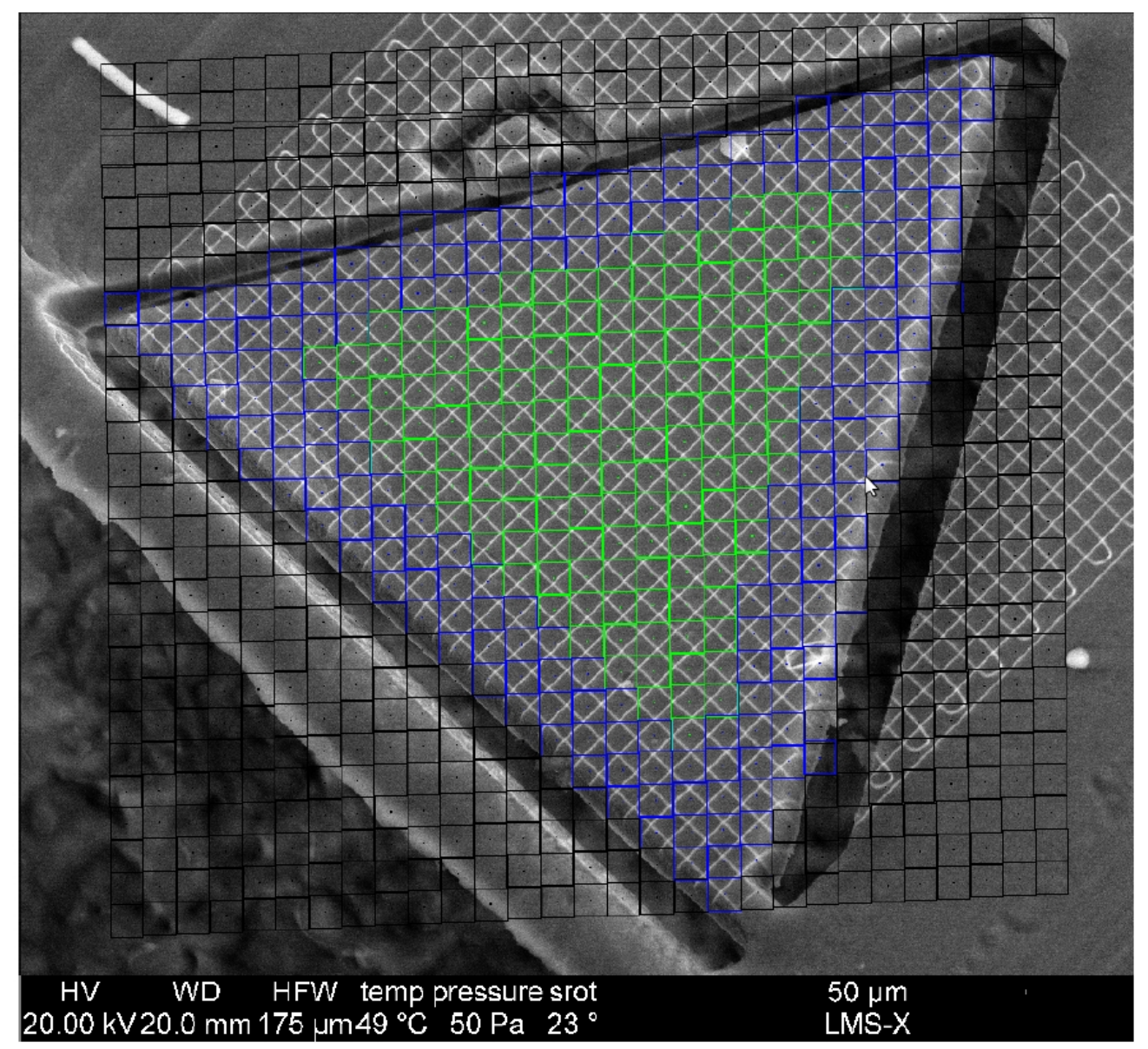

Figure 5: The measurement grid for computing the expansion of triangle during the heating test. 


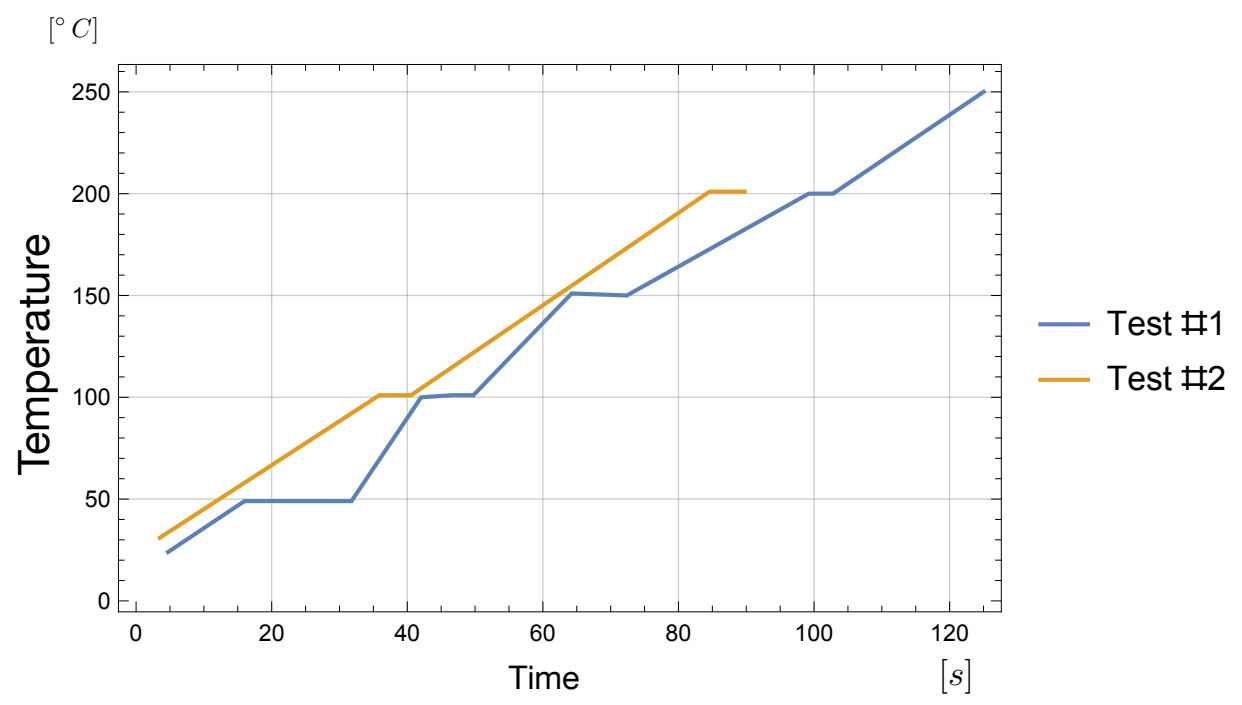

Figure 6: The temperature history during the heating of the aluminum inlet, test \#1, and the complete structure of the unit cell, test \#2. 


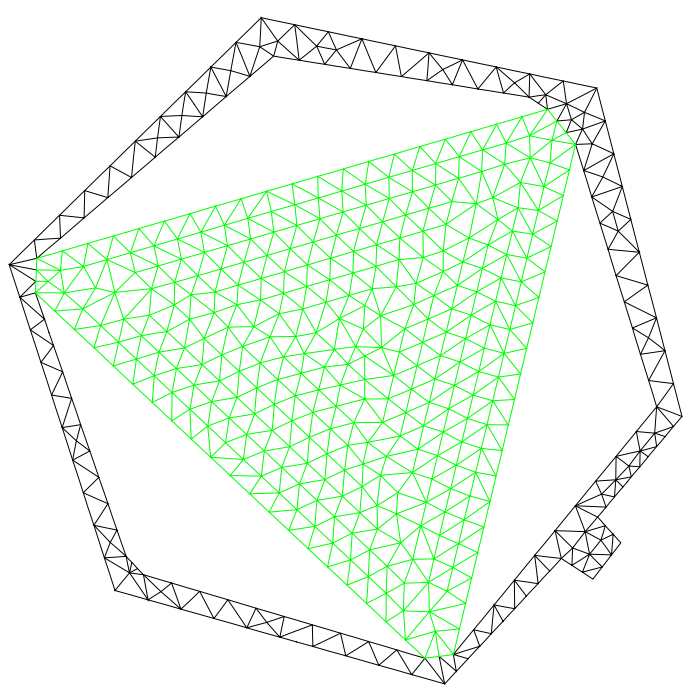

GIBI FECIT

(a) initial mesh

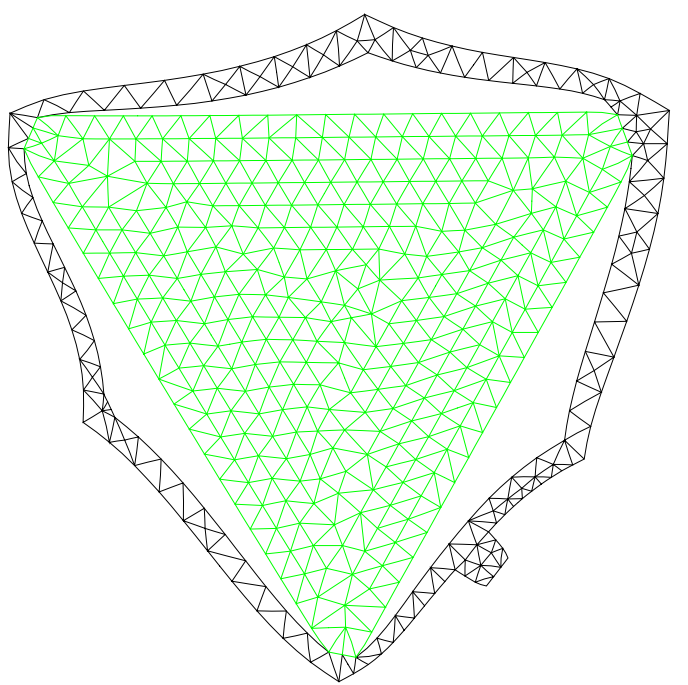

GIBI FECIT

(b) deformed mesh

Figure 7: Upper view of bimaterial unit cell: (a) initial and (b) deformed mesh by an amplification factor of 100 . at $100^{\circ} C$. 


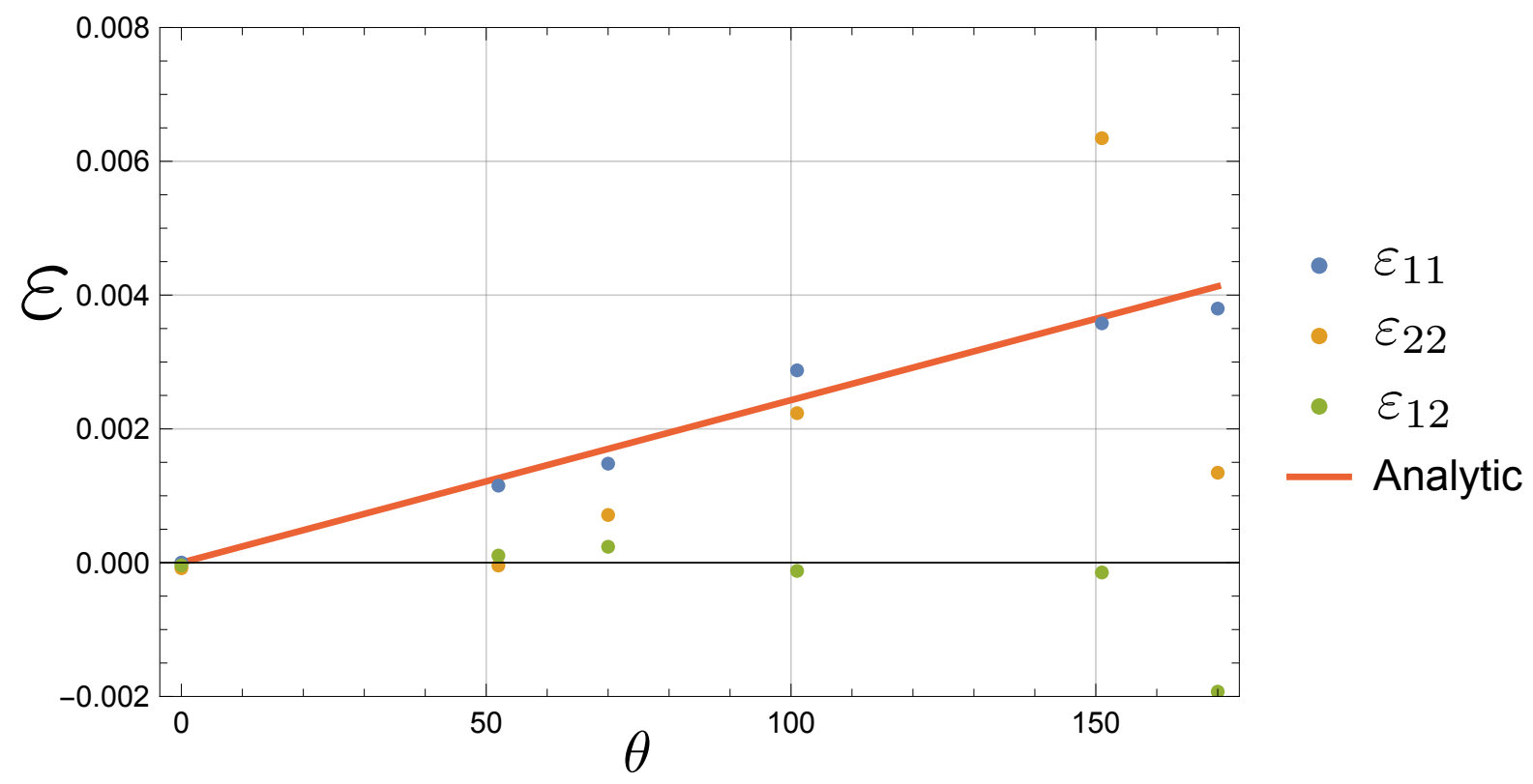

Figure 8: Evolution of the mean measured strain of the free aluminum triangular inlet as a function of temperature and comparison with the linear evolution predicted by a CTE of $\alpha_{2}=23.1 \mathrm{ppm} /{ }^{\circ} \mathrm{C}$. 


\section{$\varepsilon_{11}$}

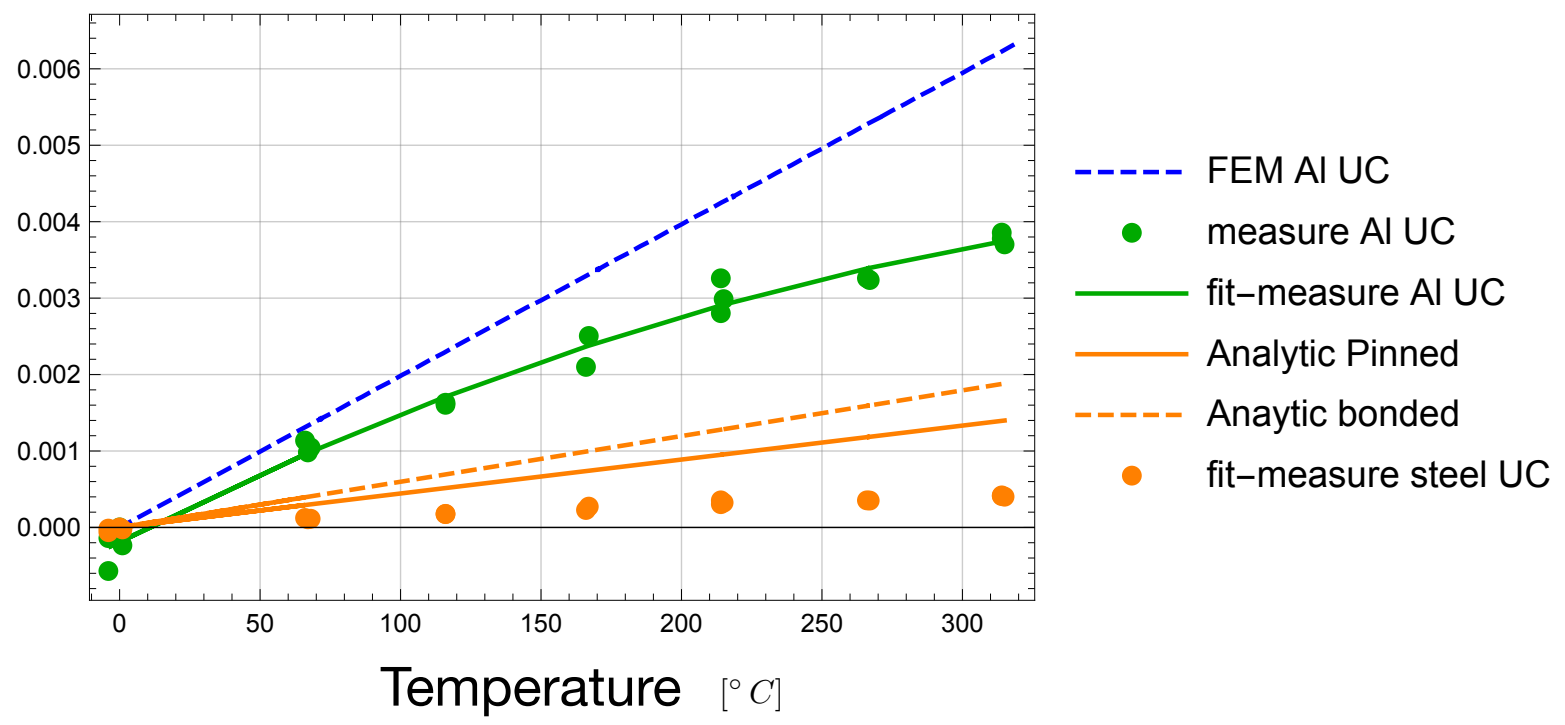

Figure 9: Evolution of the mean strain of the aluminum inlet, the outer steel hexagon as a function of temperature and compared with results from finite elements and analytic expression of CTE, [1, and 2,. 